\title{
IDENTIFIKASI KANDUNGAN BORAKS PADA BAKSO DI \\ KABUPATEN BULUKUMBA
}

\author{
${ }^{1}$ Arfiani Nur \\ ${ }^{2}$ Artati
}

1Program Studi DIII Analis Kesehatan Stikes Panrita Husada Bulukumba ${ }^{2}$ Program Studi DIII Analis Kesehatan Stikes Panrita Husada Bulukumba

\section{Alamat Koresponden:}

Program Studi DIII Analis Kesehatan

Sekolah Tinggi Ilmu Kesehatan Panrita Husada

Bulukumba, 04132514721

Hp. 085230970706

Email: arfianinur@gmail.com 


\begin{abstract}
ABSTRAK
Penelitian ini berlatar belakang Boraks merupakan senyawa kimia dengan nama natrium tetraborat (NaB4O7 10 $\mathrm{H} 2 \mathrm{O}$ ). Jika larut dalam air akan menjadi hidroksida dan asam borat (H3BO3). Boraks sering disalah gunakan sebagai bahan tambahan pangan, boraks tidak diizinkan penggunaannya dalam makanan yang disesuaikan dengan Permenkes RI No.1168/Menkes/Per/X/1999 tentang bahan pangan. Tujuan penelitian ini untuk mengetahui kandungan boraks pada bakso di daerah kabupaten Bulukumba. Jenis penelitian ini merupakan penelitian eksperimen laboratorik menggunakan metode uji kualitatif. Sampel penelitian ini adalah sampel bakso. Dengan metode kertas kurkumin tidak menghasilkan perubahan warna pada kertas kurkumin, warna kertas kurkumin tetap kuning yang menunjukkan bahwa sampel tersebut tidak mengandung bahan berbahaya boraks.
\end{abstract}

Kata Kunci : Boraks, Bakso, Metode Kurkumin

\begin{abstract}
Abstrack
The background of this research is that Borax is a chemical compound called sodium tetraborate (NaB407 10 $\mathrm{H} 20$ ). If dissolved in water it will become hydroxide and boric acid (H3B03). Borax is often misused as an additional ingredient not permitted in foods that are adapted to Permenkes RI No. 1168 / Menkes / Per / X / 1999 concerning food ingredients. The purpose of this study was to determine the content of borax in meatballs in the district of Bulukumba. This type of research is a laboratory experimental study using qualitative test methods. The sample of this study was that curcumin paper did not produce changes in color on curcumin paper, the color of curcumin paper remained yellow indicating that the sample did not contain hazardous borax.
\end{abstract}

\title{
Keywords: Borax, Meatballs, Curcumin Method
}


PENDAHULUAN

Kota Kabupaten Bulukumba senantiasa mengalami perkembangan secara horizontal dari waktu kewaktu, sejak tahun 90-an termasuk perkembangan wilayahnya secara fisik. Sebagaimana diketahui bahwa pangan merupakan kebutuhan dasar manusia yang terpenting, tanpa pangan manusia akan sulit melakukan aktivitas sehari-hari.Pangan yang aman untuk dikonsumsi adalah pangan yang tidak mengandung bahanbahan yang dapat membahayakan kesehatan atau keselamatan manusia misalnya bahan yang dapat menimbulkan penyakit atau keracunan.(Yulianto,2013).

Daging sapi merupakan salah satu sumber pangan yang sangat potensial, karena memiliki kandungan gizi yang tinggi dan asam amino esensial yang lengkap bagi tubuh. Harganya yang relatif mahal menyebabkan konsumsi daging oleh masyarakat masih relatif rendah. Banyak upaya-upaya yang telah dilakukan dalam proses pengolahan daging sapi agar dapat terjangkau oleh masyarakat. Salah satu produk olahan daging sapi tersebut adalah bakso.(Anonimus, 2011 dalam Fuadi,2016).

Bakso didefinisikan sebagai daging yang dihaluskan, dicampur dengan tepung pati, lalu dibentuk bulat-bulat dengan tangan sebesar kelereng atau lebih besar dan dimasukkan ke dalam air panas jika ingin dikonsumsi. Daging dalam pembuatan bakso mempunyai peran yang sangat dominan, karena daging merupakan bahan utamanya. Aroma, rasa dan tekstur bakso dapat dipengaruhi oleh daging yang digunakan, sehingga sangat menentukan mutu organoleptik bakso yang dihasilkan.(Fuadi,2016).

Konsentrasi bahan pengawet yang diizinkan oleh peraturan bahan pangan sifatnya adalah penghambatan dan bukannya mematikan organismeorganisme pencemar, oleh karena itu sangat penting bahwa populasi mikroba dari bahan pangan yang akan diawetkan harus dipertahankan seminimum mungkin dengan cara penanganan dan pengolahan secara higienis.Adapun bahan kimia berbahaya yang bukan ditujukan untuk makanan, justru ditambahkan kedalam makanan adalah formalin, boraks, rhodamin $\quad \mathrm{B}, \quad$ methanil yellow.(Widayat,2011).

Boraks bersifat toksik bagi sel, berisiko terhadap kesehatan manusia yang mengonsumsi makanan mengandung boraksAkibat yang dapat ditimbulkan antara lain anoreksia, berat badan turun, muntah, diare, ruam kulit, kebotakan (alopesia), anemia, dan konvulsi. 
Konsumsi terus menerus dapat mengganggu peristaltik usus, kelainan susunan saraf, depresi, dan gangguan mental.(Istiqomah dkk, 2016).

Penambahan boraks bertujuan untuk menambah kerenyahan, meningkatkan kekenyalan, memberikan tekstur padat, dan memberikan rasa gurih serta bersifat tahan lama terutama pada makanan yang mengandung pati atau terigu (Efrilia dkk, 2016).

Berdasarkan hal tersebut diatas maka penulis berkeinginan untuk melihat sejauh mana kandungan boraks pada bakso didaerah kabupaten Bulukumba.

\section{METODE}

Jenis penelitian ini adalah eksperimen laboratorik untuk mengetahui kandungan boraks pada bakso di daerah kabupaten Bulukumba. Penelitian ini telah dilaksanakan di Laboratorium STIKES Panrita Husada Bulukumba.

\section{Alat Dan Bahan Penelitian}

1. Alat

Alat yang digunakan dalam penelitian ini adalah Mortar dan Pastel, Batang pengaduk, Labur ukur, $100 \mathrm{ml}$, Pipet pasteur, Erlenmeyer, $250 \mathrm{ml}$, Neraca analitik, Gelas arloji, Gelas ukur, 250 $\mathrm{ml}$, Sendok tanduk, Botol semprot,
Corong gelas, Tabung reaksi, Pinset, Rak tabung, Blender, Centrifuge.

2. Bahan

Bahan yang digunakan adalah Sampel bakso, Kertas kurkumin, Aquadest, Kertas saring, $\mathrm{HCl} 4 \mathrm{~N}$.

\section{Prosedur Penelitian}

1. Metode

Metode pemeriksaan dalam penelitian ini adalah metode eksperimen laboratorik dengan uji kualitatif

2. Prinsip

Prinsip kerja dalam identifikasi boraks pada sampel bakso dibatasi pada uji warna.

3. Prosedur Kerja

a. Pra analitik

1) Sterilisasi Alat

Beberapa alat yang digunakan terlebih dahulu di cuci dengan detergen dan dibilas dengan air suling. Untuk alat-alat yang tahan pemanasan tinggi disterilkan dengan menggunakan oven pada suhu $180^{\circ} \mathrm{C}$ selama 2 jam.

2) Pembuatan Larutan Kontrol $\mathrm{Na}_{2} \mathrm{~B}_{4} \mathrm{O}_{5}(\mathrm{OH})_{4} .8 \mathrm{H}_{2} \mathrm{O}$

a) Konsentrasi $1 \%$ Alat dan bahan yang
digunakan disiapkan 
secara lengkap dalam

kondisi kering dan

bersih. Ditimbang $1 \mathrm{~g}$

Natrium Tetraboraks.

Kemudian dilarutan

kedalam aquadest 100

$\mathrm{mL}$ dalam labu ukur

$100 \mathrm{~mL}$.

b) Konsentrasi $0,1 \%$

Alat dan bahan yang

digunakan disiapkan

secara lengkap dalam

kondisi kering dan

bersih. Dipipet $10 \mathrm{~mL}$

larutan Natrium

tetraboraks dari

konsentrasi $1 \%$. Lalu

diencerkan dengan 100

$\mathrm{mL}$ aquadest dalam labu

ukur $\quad 100 \mathrm{~mL}$,

dimasukkan kedalam

botol reagen dan beri

label

c) Konsentrasi $0,01 \%$

Alat dan bahan yang

digunakan disiapkan

secara lengkap dalam

kondisi kering dan

bersih. Dipipet $10 \mathrm{~mL}$

larutan Natrium

tetraboraks dari

konsentrasi $\quad 0,1 \%$.
Kemudian diencerkan dengan $100 \quad \mathrm{~mL}$ aquadest dalam labu ukur 100mL, lalu masukkan kedalam botol reagen.

d) Konsentrasi 0,001\%

Alat dan bahan yang digunakan disiapkan secara lengkap dalam kondisi kering dan bersih. Dipipet $10 \mathrm{~mL}$ larutan Natrium tetraboraks dari konsentrasi $\quad 0,01 \%$. Kemudian diencerkan dengan $100 \mathrm{~mL}$ aquadest dalam labu ukur $100 \mathrm{~mL}$, lalu masukkan kedalam botol reagen.

e) Konsentrasi $0,0001 \%$

Alat dan bahan yang digunakan disiapkan secara lengkap dalam kondisi kering dan bersih. Dipipet $10 \mathrm{~mL}$ larutan Natrium tetraboraks dari konsentrasi $\quad 0,001 \%$. Kemudian diencerkan dengan $100 \mathrm{~mL}$ aquadest dalam labu ukur 
100mL, lalu masukkan

kedalam botol reagen.

3) Pembuatan Larutan Blanko

Larutan blanko diambil dari aquadest.

4) Uji Kertas Kurkumin

Alat dan bahan yang digunakan disiapkan secara lengkap dalam kondisi kering dan basah. Dipipet masing-masing $1 \mathrm{~mL}$ larutan konsentrasi $1 \%, 0,1 \%$, $0,01 \%, 0,001 \%, 0,0001 \%$. Dimasukkan kedalam tabung reaksi dan beri label. Selanjutnya masukkan kertas kurkumin kira-kira 1 $\mathrm{cm}$ dan biarkan terendam seluruhnya sekitar1-2 menit. Lalu keringkan pada suhu ruangan. Amati perubahan kertas kurkumin.

b. Analitik

Alat dan bahan yang digunakan disiapkan secara lengkap. Ditimbang $\pm 25 \mathrm{~g}$ contoh sampel, lalu sampel dihaluskan dengan mortal pastel/ blender sambil ditambahkan $25 \mathrm{~mL}$ aquadest. Selanjutnya saring dengan kertas saring. Ambil larutan yang telah disaring sebanyak $1 \mathrm{~mL}$ lalu masukkan kedalam tabung reaksi. Selanjutnya masukkan kertas kurkumin kira-kira $1 \mathrm{~cm}$ dan birkan terendam seluruhnya. Lalu keringkan pada suhu ruangan dan amati perubahan warna pada kertas kurkumin.

c. Pasca analitik

Sampel dengan metode kertas kurkumin tidak menghasilkan perubahan warna pada kertas kurkumin, warna kertas kurkumin tetap kuning yang menunjukkan bahwa sampel tersebut tidak mengandung bahan berbahaya boraks.

Berdasarkan hasil penelitian yang telah dilakukan terhadap sampel bakso dapat diketahui bahwa semua sampel yang telah diuji di laboratorium dengan metode kertas kurkumin dan uji warna tidak menghasilkan perubahan warna pada kertas kurkumin, dan pada uji warna. warna kertas kurkumin tetap kuning yang menunjukkan bahwa sampel tersebut tidak mengandung bahan berbahaya boraks. Apabila dengan metode kertas kurkumin menghasilkan perubahan warna kertas dari kuning menjadi merah kecoklatan, ini menunjukkan bahwa sampel tersebut mengandung boraks. 


\section{PEMBAHASAN}

Meskipun bukan pengawet makanan, boraks sering pula digunakan sebagai pengawet makanan. Selain sebagai pengawet, bahan ini berfungsi pula mengenyalkan makanan. Makanan yang sering ditambahkan boraks diantaranya adalah bakso, lontong, mie, kerupuk, dan berbagai makanan tradisional seperti "lempeng" dan "alenalen". Di masyarakat daerah tertentu boraks juga dikenal dengan sebutan garam bleng, bleng atau pijer dan sering digunakan untuk mengawetkan nasi untuk dibuat makanan yang sering disebut legendar atau gendar (Yuliarti, 2007). Hal tersebut diperkuat dengan hasil penelitian Silalahi dkk yang menunjukan bahwa $80 \%$ dari sampel bakso yang diperiksa ternyata mengandung boraks dan kadar boraks yang ditemukan berkisar antara 0,08-0,29\% dari berbagai lokasi yang diteliti, hasil tersebut sejalan dengan hasil penelitian yang dilakukan Sugiyatmi (2006) yang menunjukkan bahwa beberapa jenis makanan jajanan tradisional yang dijual di pasar-pasar Kota Semarang, terutama gendar, tercemar bahan toksik boraks.

Hasil penelitian yang telah dilakukan terhadap sampel bakso dapat diketahui bahwa semua sampel yang telah diuji di laboratorium dengan metode kertas kurkumin dan uji warna tidak menghasilkan perubahan warna pada kertas kurkumin maupun pada uji warna, warna kertas kurkumin tetap kuning yang menunjukkan bahwa sampel tersebut tidak mengandung bahan berbahaya boraks.Hasil dari penelitian ini sejalan dengan hasil penelitian yang dilakukan oleh Triastusi dkk (2013) yang menyatakan bahwa bahwa bakso yang dianalisis dengan metode uji nyala, uji warna kertas kurkuma, uji warna kertas tumerik dan Spektrofotometri UVVis membuktikan kelima sampel bakso yang di produksi yaitu, sampel A (Bahu), sampel B (Batukota I), sampel C (Batukota II), sampel D (Kleak), dan sampel E (Pakowa) yang beredar di Kota Manado tidak teridentifikasi adanya boraks dan bebas dari kandungan boraks.

Sering mengkonsumsi makanan berboraks akan menyebabkan gangguan otak, hati, lemak dan ginjal. Dalam jumlah banyak, boraks menyebabkan demam, anuria (tidak terbentuknya urin), koma, merangsang sistem saraf pusat, menimbulkan depresi, apatis, sianosis, tekanan darah turun, kerusakan ginjal, pingsan bahkan kematian (Widyaningsih dan Murtini, 2006).

Dalam hal ini perilaku seorang penjual sangat mempengaruhi kualitas dari makanan yang akan mereka jual. Perilaku pada dasarnya berorientasi pada tujuan. Dengan perkataan lain, perilaku kita pada umumnya dimotivasi oleh suatu keinginan 
untuk mencapai tujuan tertentu. Tujuan spesifik tersebut tidak selalu diketahui secara sadar oleh individu yang bersangkutan (Winardi, 2004). Skinner (1938) dalam Winardi (2004) seorang ahli psikologi merumuskan bahwa perilaku merupakan respons atau reaksi seseorang terhadap stimulus (rangsangan dari luar), oleh karena perilaku itu terjadi melalui proses adanya stimulus terhadap organisme dan kemudian organisme tersebut merespon.

Berdasarkan pada hasil analisis dan uraian di atas maka dapat dikatakan bahwa semua penjual memiliki pengetahuan dan sikap yang baik. Tingkat pengetahuan dan sikap merupakan salah satu faktor penting agar tidak terjadi pencemaran bahan toksin boraks.

\section{KESIMPULAN dan SARAN}

Berdasarkan penelitian yang telah dilakukan di Laboratorium Analis Kesehatan STIKES Panrita Husada Bulukumba bahwa pada sampel bakso tidak ditemukan adanya kandungan senyawa boraks yang ada pada bakso didaerah kabupaten Bulukumba.

Diharapkan untuk berhati hati dalam mengkonsumsi Bakso dalam jumlah banyak dan perlu tindak lanjut dari Dinas Kesehatan Setempat.

\section{DAFTAR PUSTAKA}

Depkes R.I. 2002. Pedoman Penggunaan Bahan Tambahan Pangan bagi Industri. Jakarta

Depkes 41/MA/93. 1993. IdentifikasiBoraks dalam Makanan. dalam:Metode Analisis. Pusat Pemeriksaa Obat dan Makanan. Direktorat Jendral Pengawasan Obat dan Makanan. Departemen Kesehatan RI; Jakarta.

Efrilia,M. Prayoga,T. dan Nur,M., 2016. Jurnal Ilmiah Ibnu Sina. Identifikasi Boraks dalam Bakso di Kelurahan Bahagia Bekasi Utara Jawa Barat dengan Metode Analisa Kualitatif 1(1) :113-120

Fuadi,R. Razali. Novita,A. Suryaningsih. Ismail. dan Teuku,R,F., 2016.jurnal Medika Veterinaria. Pemeriksaan Kandungan Boraks Pada BaksoDaging Sapi di Kabupaten Pidie Jaya 10(2) : 123-124

Hartati,F,K., 2017. Jurnal Teknologi Proses dan Inovasi Industri. Analisis Boraks Secara Cepat, Mudah, dan Murah Pada Kerupuk 2(1) : 33-37

Istiqomah,S. sudarwanto,M,B. dan Etih,S., 2016. Jurnal Sain Veteriner. Penambahan Boraks dalam Bakso dan Faktor Pendorong 
Penggunaannya Bagi Pedagang

Bakso di Kota Bengkulu 34(1) : 1-8

Risnawati,K. Wunas,S. dan Roland,B.,

Tanpa Tahun. Daya tarik dan Daya

Dorong Perkembangan Kota

Kabupaten Bulukumba Sulawesi

Selatan

Sultan,P. Sirajuddin,S. dan Ulfah,N., Tanpa Tahun. Analisis Kandungan Zat pengawet Boraks pada Jajanan

Bakso di SDN Kompleks Mangkura

Kota Makassar. Universitas

Hasanuddin Makassar

Suradi,K., 2007. Jurnal Ilmu Ternak .

Tingkat Kesukaan Bakso dari
Berbagai Jenis Daging Melalui

Beberapa pendekatan Statistik 7(1) : $52-57$

Tubagus,I. Citraningtyas,G. dan Fatmawali., 2013. Jurnal Ilmiah Farmasi. Identifikasi dan Penetapan Kadar Boraks dalam Bakso Jajanan di Kota Manado 2(04) : 142-148

Widayat,D., 2011. Uji Kandungan Boraks pada Bakso.Universitas Jember Yulianto,D.,2013. Analisis Boraks dalam Sampel bakso Sapi I, II, III, IV, V, VI, VII, VIII yang Beredar di Pasar Soponyono dan Pasar Jagir 2(2) : 19 


\section{Tabel 1}

Hasil pemeriksaan kandungan boraks pada bakso di Kabupaten Bulukumba

\begin{tabular}{ccccc}
\hline No & Kode Sampel & $\begin{array}{c}\text { Uji Kertas } \\
\text { Kurkumin }\end{array}$ & Uji Warna & Ket. \\
\hline 1 & A & Negatif & Negatif \\
2 & B & Negatif & Negatif \\
3 & C & Negatif & Negatif \\
4 & D & Negatif & Negatif \\
5 & E & Negatif & Negatif \\
6 & F & Negatif & Negatif \\
7 & G & Negatif & Negatif \\
8 & H & Negatif & Negatif \\
9 & I & Negatif & Negatif \\
10 & J & Negatif & Negatif \\
11 & K & Negatif & Negatif \\
12 & L & Negatif & Negatif \\
13 & M & Negatif & Negatif \\
14 & N & Negatif & Negatif \\
15 & O & Negatif & Negatif \\
\hline
\end{tabular}

